\section{Yellow light on L-tryptophan}

MORE than two years after batches of a genetically engineered amino-acid food supplement were first implicated in 27 deaths from a rare blood disorder, the jury is still out over whether recombinant-DNA technology can be given any blame for the incident. But new data from animal experiments suggest that L-tryptophan in any form - not just the batches produced by the Japanese company Showa Denko that were linked to the deaths - may be inherently dangerous. The new results are likely to put renewed pressure on the US Food and Drug Administration (FDA) to regulate amino-acid food supplements as drugs, as the agency reviews its policy on the issue.

Opponents of genetic engineering, led by Jeremy Rifkin of the Foundation on Economic Trends, made the Showa Denko incident a cause célébre once it emerged that the 1989 deaths from eosinophiliamyalgia syndrome (EMS) were associated with particular batches of L-tryptophan made by the Japanese company after it had introduced a new genetically engineered bacterial strain to produce the amino acid (Nature 346, 787; 1990). Rifkin argued that the FDA should stop licensing new genetically engineered products until there had been a full inquiry into the deaths and a thorough review of the agency's regulation of biotechnology products. Late last month, the FDA denied Rifkin's petition, concluding that biotechnology offers no unique hazards and thus should not be regulated any differently than other methods of producing drugs.

For two years, researchers at Showa Denko and many laboratories in the United States have been struggling to discover just what caused the 1989 tragedy. Suspicion has focused on a compound called 1-1'-ethylidenebis[tryptophan], or EBT, which was present in far greater quantities in the case-linked L-tryptophan than in earlier batches produced by Showa Denko. EBT is a dimer consisting of two L-tryptophan molecules, produced by the reaction of the amino acid with acetaldehyde. According to Showa Denko, EBT did not seem to be present in fermentation broth containing the genetically engineered $\mathrm{Ba}$ cillus amyloliquefaciens, but instead appeared later in the production process, during the purification of L-tryptophan. Showa Denko researchers have also failed to find any difference in the amounts of acetaldehyde found in fermentation broths containing their old bacterial strain and those with the new genetically engineered strain at which Rifkin had pointed the finger of blame.

Because Showa Denko reduced the amount of powdered carbon in its purification system at the same time as it introduced the new genetically engineered bac- terial strain, these findings would seem to absolve genetic engineering from blame - provided that it was EBT that caused the EMS outbreak.

The new results, which will be presented at the American College of Rheumatology's annual meeting in Boston next month, are from a study designed to discover if EBT could have caused the EMS cases (which affected more than 1,500 Americans in addition to the 27 who died). Lori Love, an FDA scientist working with National Institute of Mental Health researchers, says that her team's results do indicate that EBT was involved in the EMS outbreak: rats treated for six weeks with the EMS-associated batches of L-tryptophan, and those treated with EBT alone, develop pathologic changes similar to those seen in EMS.

But Love and her colleagues have also found that rats treated with batches of Ltryptophan not linked with the EMS cases - and not produced with genetically engineered bacteria-developed similar symptoms, though in a less severe form. According to Love, the new study casts doubt on the safety of consuming large quantities of L-tryptophan. The data support previous studies, she says, that postulated a role for L-tryptophan in illnesses

\section{Melbourne}

EFFORTS to commercialize the research activities of the Commonwealth Scientific and Industrial Research Organisation (CSIRO) have cost the agency dearly, a government audit has found. The Australian National Audit Office estimates that CSIRO, Australia's biggest science agency, today spends most of its annual budget on outside research projects and says commercial research is being funded at the expense of basic science.

In 1988, the government directed CSIRO to obtain 30 per cent of its funding from external sources, which it has finally achieved this year. By doing so, however, it has diverted much of its resources and core activity into supporting industrybased research projects or attracting external funds from competitive grant schemes. "As a result, CSIRO is at risk of losing full control of its research and development programme," the auditors concluded. The report, which is critical of CSIRO's business dealings and management practices, says CSIRO personnel are negotiating commercial deals with an inadequate grasp of how much any agreed research and development (R\&D) project will cost CSIRO. In particular, it found that undervaluing its contributions to some joint that produce fibrous tissue in the skin, muscles and the body's organs.

Robert Hill, from the Centers for Disease Control in Atlanta, who collaborated on the study, points out that, in addition to EBT, a number of other compounds which have not yet been identified - also seem to be associated with the EMS cases. Until these compounds are isolated and tested in the animal model, it will not be possible to determine for certain whether or not these other compounds are implicated in EMS. The data to date indicate that there is no role of genetic engineering in the formation of EBT.

The new results come just as FDA is reconsidering its policy on amino-acid food supplements. At present, FDA does not require amino acids to be regulated as drugs. But some amino acids are known to be metabolically active. L-tryptophan, for instance, is metabolized to the neurotransmitter serotonin and was taken by many of the EMS victims to relieve depression, insomnia or other nervous disorders. The suggestion that taking any L-tryptophan preparation could increase the risk of developing EMS will add to the pressure voiced at a congressional hearing during the summer -- on FDA to regulate the US market in amino-acid food supplements. Neighbouring Canada already treats these products as drugs.

Peter Aldhous

\title{
Costly commercialization
}

ventures has led to cases where CSIRO's equity was "not proportionate" with its investment.

In the past three years, CSIRO has moved heavily into external funding arrangements, joint ventures and commercialization deals with private industry. By 1990 , it was receiving $\$ 167$ million (about 26 per cent of its income) from non-budgetary sources, chiefly research corporations in the meat, grain and wool industries which traditionally have obtained CSIRO's intellectual property at well below full cost. CSIRO also holds equity in 12 private companies, with interests ranging from metals processing to aviation simulation.

CSIRO has shrugged off the report, claiming it says nothing new about the effects of the 30 per cent external funding target. Chief executive John Stocker has acknowledged that some early agreements were poor, but says CSIRO is pushing the federal government for policy changes that would force the rural industries and others to pay more for their CSIRO-derived R\&D. "The [auditors] would have done better to support CSIRO's advocacy of these policy changes to the Government rather than imply deficiency on CSIRO's part," he said. Brett Wright 